\title{
On the Submergence of the Atlantic Telegraph Cable
}

\section{Captain M. S. Nolloth R.N}

To cite this article: Captain M. S. Nolloth R.N (1858) On the Submergence of the Atlantic Telegraph Cable, Royal United Services Institution. Journal, 2:5, 96-109, DOI: 10.1080/03071845809415899

To link to this article: http://dx.doi.org/10.1080/03071845809415899

册 Published online: 11 Sep 2009.

Submit your article to this journal $₫$

Џll Article views: 2

Q View related articles $₫$ 


\section{ON THE SUBMERGENCE OF TIE ATLANTIC TELEGRAPH CABLE.}

BY C.PTAIN MI. S. NOLIOTH, R.N.

BEFORE attempting to occupy your attention for a while, I wish to say that, with one or two obvious exceptions, the following remarks were written a considerable time ago; that is, shortly after reading in the public papers the official account of the failure to submerge the Atlantic Cable, and when there seemed some reason to fear that, from the degree of success attained, no alterations in the old mode of procedure would be made, and no preliminary experiments thought necessary to increase the probabilities of success at the next endeavour.

But it is well known that since that period the promoters of this great and difficult undertaking have been busily engaged in providing the most promising plans for future action, and that, besides the aid of the able gentlemen in their employ, they hare sought advice from men eminent for their scientific acquaintance with the nature of the various details upon which success depends. Under these circumstances I desired to withdraw the few plain remarks which $I$ had been invited to prepare, but was requested to read them as originally intended.

The Report alluded to contains the following passages:

"After leaving Valencia the paying-out of the cable progressed most satisfactorily until inmediately before the mishap."

" $\Lambda$ s the water deepened, it was necessary to place some further restraint upon it by applying pressure to the friction-rollers, and this was gradually and cautiously increased from time to time as the speed of the cable compared with that of the ship and the depth of the soundings showed to be necessary."

After deepening from 550 to 1,750 fathoms, "As the water deepened the proportionate speed of the cable advanced, and it was necessary to increase the strain by degrees."

After paying out 255 miles, "Having reached 2,000 fathoms, it was necessary to increase the strain." 
Apparently six or seven hours after having reached 2,000 fathoms, "The speed of the cable gained considerably upon that of ship, and while the rate of the latter was about three knots the cable was running out from $5 \frac{1}{2}$ to $5 \frac{3}{4}$ knots per hour. The strain was then raised." "This was not found sufficient to check the cable, "the wind and sen increasing, and a current at the same time carrying the cable at an angle with the ship's course." The retarding force was therefore increased; "and then again, in consequence of the speed continuing to be more than it would have been prudent to permit. By this the rate of the cable was brought to a little short of five knots, at which it continued stcadily until it parted, the length paid out at that time being $\mathbf{3 8 0}$ miles."

While the Report admits that the origin of the accident was undoubtedly the amount of retarding strain, it is asserted that had the machine been properly manipulated at the time it could not possibly have taken place, and that no alteration from the present cable would be advisable if another had to be constructed, "its weight in water being so adjusted to the depth that the strain is within a manageable scope."

With real.deference for the judgment of the writer of the above, whose skill and experience in such matters are known, I find it difficult to adopt in its unqualified shape the opinion quoted in the last paragraph, or to admit that " the paying-out of the cable progressed most satisfictorily until immediately before the mishap," as announced in the first. In my humble opinion the facts rather warrant the belief that the specific gravity (about 3.5) of the cable is too great for not only the greatest, but the great depths, and that the restraint necessarily exercised on board to prevent a dangerously accelerated descent, and to maintain a proper relation between the speed of ship and that of cable, afforded, from the entrance upon the deeper and rougher water, a too doubtful prospect of success, considering the great distance to be run.

We see that from the commencement it was necessary to use a retarding force-that with increasing depths additional force had to be applied-and that when at the greatest depth attained-at the threshold of the real work-the demand for cable above that due to the advance of the ship went on increasing till the issue was at

VOL. II. 
nearly twice the speed of the latter, and additional restraint was applied till shortly before the fracture.

Now, putting aside the probability of mecting worse weather, it can searcely be concluded that when the cable parted the last demand for additional restraint had been made: but, allowing that it had then seached its maximum, when it is considered that the course lay over a wide and ever-restless ocean-that the connexion was between an advancing ship and several miles of line quitting with its own proper motion, ready for dangerous acceleration at any slight relaxation-that the extra strain produced at every check must be in exact proportion to the reductiou of momentum effectedit would seem that the life of the enterprise hung at every moment upon a thread, and that it was too much to have expected in so costly an undertaking that the nice manipulation required in such fast and loose play would be applied throughont the run, without one wrong and fatal turn of the wrist.

When 214 sea miles had been run, 255 statute, or 220 sea miles, of cable had issued: according to this the excess of cable over 214 miles run was only the surprisingly small quantity of 2.8 per cent. When the parting took place the ship had advanced about 270 sea miles; and had expended 380 statute or 328 sea miles of cable. Thus 108. miles of line had been expended in running the last 56 miles; so that, supposing the ship to have continued her course, with this degree of waste, till she arrived at the corresponding depth on the opposite side of the Atlantic, she would have required, for more than 1000 miles, an excess of cable nearly equal to the distance run. No doubt a small portion of this waste occurred (although it is not so stated) during the stoppage to re-adjust the cable on the shenves; but it is clenr that when fairly in very deep water the difficulties were insurmountable, and that it is fortunate that the fracture took place at so early a stage of the proceding.

The difficulties in such operations increase in a faster ratio than the depth, and this great Atlantic task is of an cossentially different character from that of the submergences hitherto effected. The vast distance alone removes it from their category: but here our risks are not only more numerous but of a far more serious nature, and, while the value imperilled is greater, accidents are less 
within the reach of remedy. It is difficult to conceive a project upon which the cost of a few decisive experiments would be more cconomically bestowed.

How many of the submergences hitherto effected, including those in comparatively shallow water, would have added to the list of failures if they had had to stand their trial throughout a run of 1600 miles! The pitcher may be often used at the well, but it will be broken at last.

On reading the Report, the question arises,-Which of the two forces was most inimical to the task in hand-gravity, or horizontal motion of the water acting against the bight of the descending cable?

Had the gradually increasing call for pressure on the brake, as the ship passed over increasing depths, been caused by the "swigging off" of currents upon a vast bight, this would have been plainly indicated by the line growing out on the quarter, and the waste would not have been confined to so small a quantity, till shortly before the accident, without a restraining force greater than the cable could have possibly borne. But, although we read that fresh demand for cable is the constant coincident of greater depth, we have no allusion to the line being drawn away at an angle with the ship's course till the late period just mentioned, when " the wind and sea increased." There can be little doubt that the reduced speed of the ship, the increasing sea, and increasing weight from depth, suffice to account for the great waste Iatterly, without the supposition of under-currents. The greater and more irregular the ship's motions the more frequently would the relense or relaxation of the brake be required, and at 2,000 fathoms great strain at any acceleration might be expected, independently of any lateral force. The oblique direction of the line was most probably owing to the ship being drifted by an upper current. The effect of this would be very different from that of deep currents acting on the bight, and would intolve little, if anything, more than the extra expenditure due to deviation from the straight course.

It is clear that, whatever be the forces, the "give-and-take" action when a force is applied above constitutes the direct danger in a sea-ray, and that the object should be to diminish it by dispensing as far as may be with the brake which brings it into play. 
The onward motion of even a large ship is not quite equable in a sea, however uniformly applied the propelling power: deep plunges forward, alternate with sudden retardations, and a scrious portion of these actions, and of the more vertical ones of the stern at "pitch" and "scend," must now and then be simultaneously resolved, to and fro, in the direction of the outgoing line. The combined effects must be at one moment a virtual relaxation of the brake, and at the next a sudden recall like the "smack" of a whip.

Let any one, when the lead has just reached the bottom in about 100 fathoms, and the line is still descending, stoop down, and suddenly gather up as much as he can at one haul. If new at such work he will be astonished at the great resistance to his recorcry of even three or four feet of a light, thin, smooth line, and it will help him to appreciate the strain that must be brought by any sudden attempt at recovery on the upper part of three or four thousand fathoms of monning line weighing 15 cwt. in water, independently altogether of friction on a circumference of nearly two inches.

Moreorer, it must have been impossible at so great a depth, by observing the angle of exit or otherwise, to make more than a very rude estimate of the form or of the length of line sustained by the retardiug agency, and this agency which created the danger, in proportion to the degree in which it was exercised, may (notwithstanding the excess, generally, of cable over distance run) have becn occasionally the means of supplying its own work, by dragging along a lengthening line. Calculations upon assumed relative speeds, depth of water, and other data, can be only of very partial application where the "constants" must be so inconstant; but, with a heavy cable requiring severe control by brake, it is clear that we are involved in a dilemma; for while great strain must be caused, eren in a calm, by maintaining a small angle of exit in deep water, dangerous relaxations and retardations must result, in a sea-way, from not maintaining a sminll angle.

Undoubtedly, if means had been provided of counteracting the reciprocating motions by long spiral springs applied to leading pulleys before the brake, the risks would have been greatly diminished; but I fear that unless we produce a uniformity of brake action, equal to that effected by the air-vessel of a firc-engine, 
we can scarcely reckon in a sea-way, throughout a long run, over great depth, upon a safe adjustment to the capricious requirements of a cable much specifically heavicr than the fluid.

Enough, however, was performed in the way of submergence to remore all doubt as to eventual, if not as to immediate, success: and, considering the experience just gained, few who rend his Report will blame the persevering Engineer for lis sanguine statement that he " secs no reason for discouragement, but has a greater confidence than ever." Recollecting the mishaps in other cases, it cannot be thought very strange if in the first attempt to span the ocean we got rather out of our depth.

But it must be borne in mind that the final object of this great work is not to lay a line across the ocean, but to place upon its bed, in its integrity, an electric conductor, and, as far as possible, so to lay it, that, after escaping fracture or partial damage from heavy jerks in its passage, its durability may not be impaired by parts being landed upon hard matter, with long intervening portions quite unsupported, however flexible. We Iearn from Captain Dayman's soundings that there are rocky and stony regions; and in these considerable irregularities of surface may be expected. Fortunately, we have reason to bclieve that there is little agitation of the lower waters; but, as the least disturbance might eventually prove fatal if considerable spaces were bridged over, we should not reckon too strongly upon this farourable circumstance nor rely unduly upon incrustation, remembering that here, as in other cases, the efficiency of the whole line-whether mechanical or electrical-is only that of the weakest section.

The undertaking to span the "bottomless deep" is in itself so surprising that we are liable to be led away from the real idea, and, in the near prospect of such a feat, to lose sight of its being only a means to an end.

It is not improbable that successful submergence would at once prove a great stimulant to similar enterprises, and that the first message across the deep would be a signal for the preparation of other ocean lines, especially if, with its lightning speed, the first should be found too slow of speech. When the great cost of such cables, independently of their submergence, is considered, it would be a great 
misfortune if, after having been constructed and laid down, they should soon lose their vital element-that, having safely reached their beds, they should shortly go to sleep and reftuse to make a sign.

Now, if the weight were such that the cable could be generally left to itself, or rather to the buoyancy of the fluid, so that, if allowed to do its worst at the greatest depth, it would expend its acceleration without having acquired too great a velocity, -in other words, if the specific gravity were so adjusted to the great depths that the unrestricted proper motion of the cable would supply the difference betrreen the distance run and the line of deposition, the great risks in a sea-way would disappear, and the great waste now inevitable at slow speed against head-winds could be easily avoided.

Experiments at the nearest 2,000 fathoins depth would nearly enough determine the specific gravity which, at the greatest depth to be encountered, would, at a given safe speed (upon which the degree of broalside, and therefore the rate of descent, would depend), allow the supposed requisite per-centage of cable over distance run. A grenter ascess of line could be iscued whenever thought advisable, not by faster descent, but by slightly slower advance of ship, which would not materially alter the angle formed by so light a cable. To provide against the cable issuing, under any circumstances, at a faster rate than that due to the ship's advance-as in the case of a strong head-wind and sea-n very simple appliance would suffice to effect the required slight retardation, without ever communicating the dangerous snatching motions of the vessel; the reverse or yielding motions would not require to be counteracted, as with a heavy cable. A delivery-drum driven by machinery would bo required, and the means, as before, of registering the issue.

On the whole, the speed of ship might be, with safety, greater than with a heavier cable, as it would require to be limited only by regard to the relative motion boyond which experience had ascertained that the cable could not be properly worked in the hold.

It is ncedless to allude to the great advantage of saving time in this undertaking, not only for the avoidance of chances of bad weather, but for the saving of cable from the ship being set out of her course by currents; in the latter economy are involved not 
only expense, but the clannces of durability, which, in several respects, must be considered as inversely to the length laid down. The more horizontal the descending cable the less must be the waste through the tendency of every portion to overshoot its berth, from the reaction of the water at right angles to the line at the points impinged upon.

A small angle of incidence, which is of so great importance in a sea-way, would be preserved by speed of ship nnd slow descent of cable without a dangerous, especially when intermitting, agency; while, instead of a cable rushing straight away on its release, the lifting stern, or any accidental stoppage in the delivery, would have not only a slight weight, but some chance of slack to veer and haul upon.

Thus, neither electric conductor nor its envelope would have efficiency hazarded by jerking motions, while freedom to attend to the ever-varying calls of gravity, without any mischicrous interference from above, where judgment as to what is taking place below must be at fault, would conduce to a deposition in conformity not only with the general profile of the ground, but with comparatively trifling irregularities.

But again the question meets us, "Can we reduce the great evil of the vertical without introducing a greater from the horizontal force?"

The report to the Directors deprecates decrease of specific gravity, alleging that "danger would arise from under-currents acting upon an increased surface during the greater time occupied in sinking."

The effect of strong lower currents is no doubt an important element for consideration supposing them to exist; for the "scare" of 2000 fathoms of $\frac{5}{8}$-inch diameter exposed to their action wonld be 625 square feet; but it seems especially formidable in regard to tension, when the "swigging-off" force is bronght into play by a strain in. termittingly applied at the upper part. Important horizontal movement of the lower waters of the open ocenn is not howrever credited by the best authorities. Wasteful expenditure of line appears most likely to result from the ship being carried ont of the direct track by upper currents; and, excepting the case of a current of trifling vertical extent, and the direction and force of which conld be ascer- 
tained and allowed for, such waste is unaroidable. Supposing only lower important currents, I should think waste from this cause also unaroidable, as not subject to safe control.

Since the above was written I lanve received a copy of the report of the soundings along the telegraphic plateau by the rery experienced officer Captain Dayman, R.N. In some of these Massey's patent machine was used with a marked line, and the two indications agreed sufficiently at very great depths to show that the line must have been carried down perpendicularly, and that therefore no current had affected it. On one of these occasions the depth registered by machine was 2,176 fathoms, but 2,400 fathoms of line had been paid out to ensure the detachment of the weight. To the surprise of himself and assistants, the 200 fathoms next to the sinker came up to the surface in one entangled coil, covered with the mud of the bottom, leaving only 24 of the 224 fathoms of extra line to be accounted for. Such facts are valuable, also, in giving confidence in ocean sounding, when executed with skill.

If it should unfortunately prove that demand for extra cable is greatly caused by vertically extensive currents sweeping away the bight, we should have to cleal with a far less manageable element than weight, and I should be little sanguine of speedy success.

When other ocenn lines are taken in hand, as they assuredly will be, the following questions will be maturely considered:

Is the wire envelope necessary for the preservation of the heart or conducting wires?

Is it necessary for the sake of rapid descent through important lower currents?

Is it necessary for safe manipulation, bearing in mind that a light cable would not be subjected to the rough usage incident to the existing brake system?

If the present Atlantic cable-which for its strength, extreme pliability, and excellent workmanship throughout has been universally admired-should be hereafter deemed too heavy for the conditions to be fulfilled, in order to diminish as far as possible the probabilities of ultimate mischance, the best expedient would appear to be extraneous buoyancy. In an undertaking on so large a scale, every application of this nature is likely to assume a formidable shape in 
regard to expense, convenience of handling, and space for stowage. Perhaps the cheapest practicable measure would be to seize coire rope along the portion intended for the great depths, the seizings being sufficiently close to prevent obstruction from the bights to the clear working of the coils.

Coire is not very much lighter than sen-water, but its buoyant effect would be assisted considerably by its "dragging " action during the oblique descent, and a given quantity of the material thus applied would give a greater aren of resistance than if laid up with, so as to form fart of, the cable itself, and without corresponding increase of rigidity.

The cost of 2-inch coire rope is about $5 l .6 s$. per mile, and rather less if of forcign manufacture.

It would perhaps be too much to state, as a possible incidental advantage, the chance of the elastic coire saving the end of the cable in the event of fracture.

Whatever be the nature of the cable employed, it would be of the highest importance if some means could be contrived of saring the end in case of accident; but here I am afraid we must say more emphatically than usual "prevention is better than cure," for it rould certainly appear from the expedients hitherto proposed that it is diffeult to devise a "save-all " which would not greatly add to the chance of total loss.

The least excusable cause of failure would be want of sufficient length of cable; but it is not at all probable that difficulty will arise on this account, the distance to be run on the great circle being 1,646, and the length of cable provided 2,400 miles.

It was originally intended to employ tro ships in simultaneously laying down from mid-way to the shores after joining ends. Supposing cqual appliances and supervision, this plan would appear greatly preferable to the one adopted, except for the greater probability of clearing the commonly boisterous neighbourhood of Ireland in farourable weather, and unless the latter were viewed as the more cautious one for a first attempt: and, indeed, with the results before us, it is cortain that had the ships made a fair start in calm weather, such as would have been chosen, a much greater length of calile would have been irrecoverably lost than is now the case, 
A short run of success from mid-way would carry each ship to comparatively safe depth; and at the fincst season of the year, when the wenther probabilities may be considered equial along the course, the choice of time at mid-way would afford a better security for farourable weather throughont, than that made at one extreme of the line.

We know that the joining of the cables mid-way in fine wenther, when neither would be submerged, would present no difficulty; but the arrival at midway with one cable on the ground at 2,000 fathoms might be fatal, whether the attempt were made or not at the time; and, if successfully made, the critical operation of handing over the strain, from the ship letting go the bight to her colleague, would then have to be performed.

A small stage to flont the bight between the ressels while splicing and when preparing to separate might be convenient; and, if made of substances not likely to have their specific levity soon impaired under pressure, it might be advantagcousiy allowed to accompany the bight to the bottom, so as to reduce the rapidity of descent.

It has been objected, that, as tro portions of the cable would be worked at the same time, extra risk of losing a great length would be incurred by the chance of fracture at both ships; but it is obvious, that, on the plan adopted, one parting necessitates the chance of a second rupture, with irrecorerable loss, in the subsequent under-running.

The probabilitics of depositing the cable in hollows would be perhaps greater when generally decreasing than when generally increasing the depth; and it is somewhat in fayour of a start from the middle-vast depth being the chief difficulty-that in costly undertakings it is, coteris paribus, better to incur the greatest inevitable risks at as early a stage as possible.

I add a few remarks on some of the various schenes which have been proposed, chiefly in the public payers.

One recommendation is, to use "perforated tin buoys, which would hold the cable after it was paid ont, preventing a strain, and gradually as they sank in their order taking it with them to the bottom." 
$\Lambda$ part from the fact that the cable seems already too much inclined throughout its course to find its way to the bottom, most practical men will allow that, even if the buoys would behave as intended, and not fill too soon or collapse, this plan is scarcely feasible throughout so great a length. Inflated bags would be preferable to tin buoys, as they would be cheaper, more easily storred away cmpty till wanted, more readily attached, more certain of buoyancy when required, and more certain of losing it at a proper time through compression.

"No Evarneer:" proposed-and surely no sailor will agree with him-to avoid injury from the sudden lifting of the stern, by "linking a number of pontoons together, and then attaching them to the stern of the vessel, so that the wreight of the cable being borne by their buoyancy, without disappearing in a calm, the tail of the line of pontoons would, when a sea did come, yield to its weight, and thus prevent a jerk that would otherwise snap the cable."

It certainly would not be safe to subject the cable to such an ordeal of "fair-lenders" in its passage to the deep. In all probability, the being held obliquely to the ship's track, and confused swells thrusting them against each other when doing their best to perform the duty required of them, would, "when a sea did come," at once render it necessary to disencumber the cable of them, or of their remains.

The recommendation to pass the cable through a trunk in the vessel's bottom near the centre of motion, is an idea which probably occurred to many acquainted with the old method of fitting our launches in the Navy; but the extreme inconvenience of this mode of exit in more than one respect-the fact that the bodily rise and fall of the ship would still have to be met, the concealment of the issuing portion, and the difficultics likely to arise with much rolling motion-seem fatal objections.

It has been proposed to inclose the cable in a gutta-percha tube of rather large diameter, for the sake of buoyancy, chiefly from the air filling the spaces between the seizings used to secure it.

The cheapest tubing likely to prove water-tight would alone cost $8 d$. or $9 d$. per foot, independently of the expense of enveloping the 
cable, which would not be so simple a process as "drawing" the gutta-percha with the wires; morcover, the contained air-if contained-would lose $\frac{1}{4}$ its buoyancy before it had descended $\frac{1}{140}$ of the way to the greatest depth. This would therefore be a plan for paying heavily for a light advantage.

Perhaps the most curious suggestion called forth by the Atlantic Cable, is the proposal to reeve it through a ring in the bottom of a vessel five miles astern of the principal, so that in the event of fracture the end would be secured by the ressel holding on the bight.

It is true that, as the retarding force of gravity on one side would equal the accelerating force on the other, there would be no possibility of an unduly heavy cable fetching way when once in motion, and either paying itself out too much under foot, or munning out to the clinch; but one ship would experience no greater immunity from the waves than the other; and when it is considered that the great difficulty in hand is rast depth-that this would be dealing with it thrice instead of once, that even a short run obliquely to the trend of the cable ahead might be fatal, that the whole cable already safely landed with portions probably lodged under rock, would hare to be raised-this scheme may almost be called, notwithstanding the farourable opinion of the "Times," "A plan for carrying away the cable after successful submergence."

Various other proposals, including "floats" and "stopwaters," have from time to time heen made, to ensure the safe deposit of the Atlantic Cable, but few of them show sufficient regard to the important items of cost, convenience of handling, and space for stowage. Solid buoys are too cumbrous for such an undertaking: hollow ones, unless of great strength, involving inconvenient weight, must burst at considerable depth from want of equal pressure within, and yielding substances would permit an equilibrium at the expense of buoyancy. These seem sufficient objections to such appliances, eren if they were practicable; but the stage to be anticipated for this great work is a ship on a stormy sea in a dark night, the ship and cable rapidly parting company.

But, since the above rnther popular suggestions were offered and 


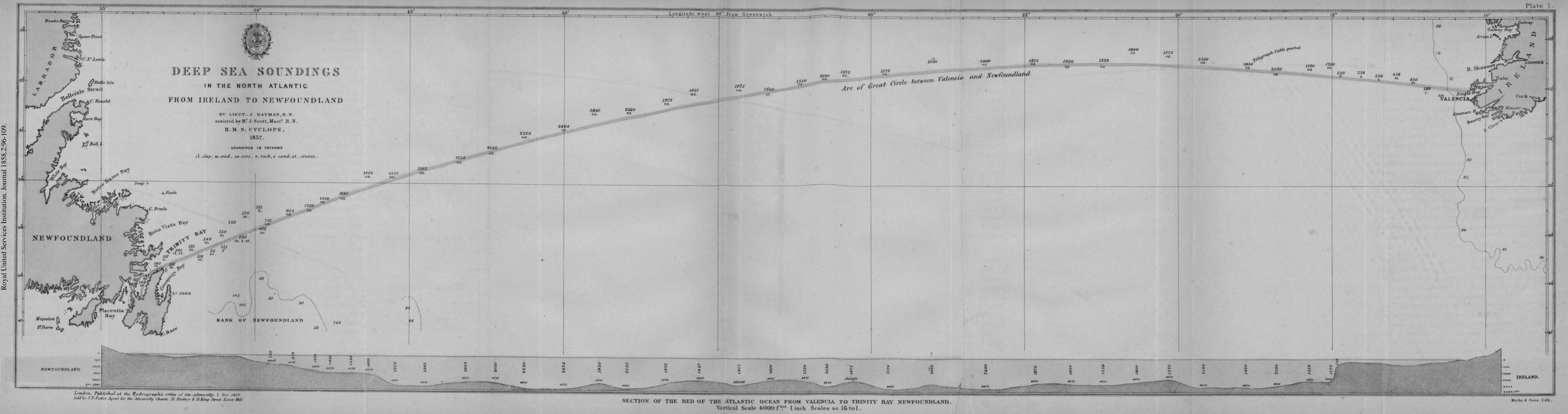


reviewed, the subject has been taken up afresh in enrnest, and the Atlantic Telegraph Company have had under their investigation in variety of ingeniously devised schemes for procuring the great desideratum under existing circumstances, viz., a more uniformly acting control over the descent of the cable, so as to meet at the greatest depths the difficulties presented by irregular motion. Moreover, the start will be from mid-way at the finest season of the year, after complete experiments, which it appenrs circumstances did not permit bcfore, so as to test as thoroughly as may be thought expedient the fitness of the new arrangements.

Under these circumstances, whatever may be the opinions as to weight, we may reasonably believe, and we must all desire, that the skill, anxiety, and public spirit manifested, will meet their reward in the safe launch of this leviathan of the deep. Evcry one must wish success to the approaching attempt to tie the Old and New World together, and hope that the bond may prove, in the fullest sense of the term, a lasting cord of commerce and civilization.

Before us is a case containing specimens of the component parts of the cable, for which the Institution is indebted to the kindness of the Atlantic Telegraph Company.

Capt. Fishoounate, in expressing his entire concurrence in the above views, stated that it was due to Capt. Nolloth that he should say that he had perused Capt. Nolloth's paper before the recent discussions on the subject took place, and had seen the sketch of a plan by him for mitigating the sudden effect of the ship's motions upon the cable, similar in principle to the means which he believed were to be adopted at the next attempt at subnergence.

N.B. The United Service Institution is indebted to the Admiralty for the accompanying diagram of the soundings along the Atlantic Telegraph Plateau. 